\title{
The best is the enemy of the good
}

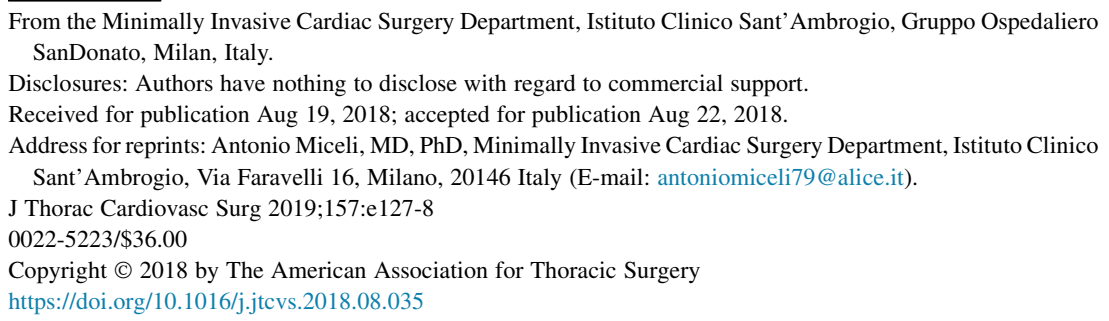

Mitral valve repair is the gold standard treatment for degenerative mitral valve regurgitation. In the last decade, several minimally invasive mitral valve repair techniques have been developed to reduce the invasiveness of the surgical procedure, offering comparable safety and quality to the conventional approach, including high freedom from mitral valve reoperation. ${ }^{1}$ The implantation of artificial chordae has definitively contributed to these excellent results. ${ }^{2}$ The willingness to be less invasive has brought the idea of the NeoChord system (NeoChord, Inc, Minneapolis, Minn), an off-pump, transapical surgical option for treating degenerative mitral valve disease on a beating heart.

In the February 2019 issue of the Journal, Heuts and colleagues $^{3}$ report an unusual complication of a successful minimally invasive mitral valve repair through a transapical beating heart approach. Specifically, a 75-year-old female patient with severe mitral regurgitation (MR) was successfully treated with 3 artificial neochordae on the P2 leaflet using the NeoChord DS 1000 system. Despite the good result at discharge, the patient presented with recurrence of severe mitral valve regurgitation 5 months later, requiring a conventional mitral valve repair through median sternotomy.

The rupture of expanded polytetrafluoroethylene (PTFE) neochordae is a rare complication in conventional mitral valve surgery. On conducting a literature review, Bortolotti and colleagues ${ }^{4}$ found only 4 cases of recurrent MR due to the late (6-14 years postoperatively) rupture of calcified expanded PTFE chordae. ${ }^{4}$ Conversely, the genesis of early chordal rupture was probably related to PTFE fatigueinduced lesion. In 2014, the authors of the Transapical Artificial Chordae Tendinae trial presented the results of mitral valve repair using the NeoChord DS1000 system. ${ }^{5}$ Of note, 2 procedure refinements were introduced during the conduct of the trial to reduce the mechanical stress: (1) the use of multiple neochordae per procedure to give an equal distribution of stress on mitral valve leaflet tissue and PTFE sutures and (2) the revision of the left ventricular apical access site toward the posterolateral wall. The latter provides a more natural orientation of implanted

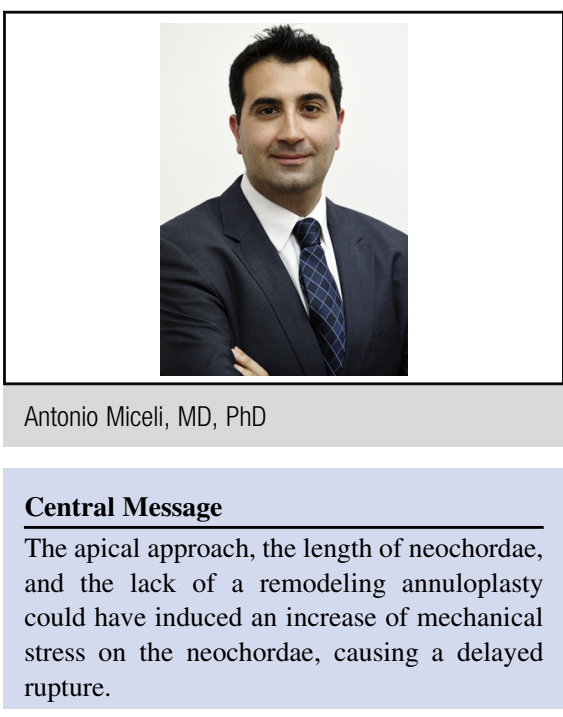

See Article page e27 in the February 2019 issue.

neochordae and shortens the length of artificial chordae, as the left ventricle anchoring point is closer to the base of the posterior papillary muscle. In an in vitro test, Caimmi and colleagues ${ }^{6}$ found that the increase of the length of artificial expanded PTFE chordae is accompanied by an increasing stiffness that may compromise the long-term resistance of the chordae, suggesting that mitral valve repairs that anchor expanded PTFE neochordae to the ventricular apex may have less durability than when anchored to the tips of the papillary muscles. In this setting, the mechanical stress induced by the "apex approach" might partially explain the early failure of mitral valve repair. Furthermore, the lack of stabilization of the entire annulus with a remodeling annuloplasty might have further increased the mechanical stress on the neochordae. A recent large European experience with transapical off-pump mitral valve repair with the NeoChord system reported a $96.7 \%$ rate success with acceptable postoperative complications. ${ }^{7}$ Although no chordal rupture occurred, Colli and colleagues $^{7}$ reported a $9 \%$ rate of redo surgery at 1 year. A limit of this procedure is that in large mitral repair centers, the recurrence of MR and mitral reoperation rates are low, between $5 \%$ and $10 \%$ at 10 years. ${ }^{8,9}$

The NeoChord DS 1000 system was developed to reduce the invasiveness of surgical procedure and avoid the cardiopulmonary bypass machine. Despite an excellent candidate, a low-risk 75-year-old woman with severe MR would have benefited from a conventional minimally 
invasive mitral valve repair, consisting of neochordae implantation and annuloplasty. This would have probably avoided the recurrence of MR. The surgical portfolio that surgeons can offer to patients is wide, and the authors have thought to give the best surgical technique in terms of invasiveness and risks. However, sometimes the best is enemy of the good!

\section{References}

1. Miceli A, Murzi M, Canarutto D, Gilmanov D, Ferrarini M, Farneti PA, et al. Minimally invasive mitral valve repair through right minithoracotomy in the setting of degenerative mitral regurgitation: early outcomes and long-term follow-up. Ann Cardiothorac Surg. 2015;4:422-7.

2. Perier P, Hohenberger W, Lakew F, Batz G, Urbanski P, Zacher M, et al. Toward a new paradigm for the reconstruction of posterior leaflet prolapse: midterm results of the "respect rather than resect" approach. Ann Thorac Surg. 2008;86: $718-25$
3. Heuts S, Kawczynski M, Olsthoorn JR, Sardari P. Late rupture of transapically beating-heart implanted NeoChords. J Thorac Cardiovasc Surg. 2019;157:e27-9.

4. Bortolotti U, Celiento M, Pratali S, Anastasio G, Pucci A. Recurrent mitral regurgitation due to ruptured artificial chordae: case report and review of the literature. $J$ Heart Valve Dis. 2012;21:440-3.

5. Seeburger J, Rinaldi M, Nielsen SL, Salizzoni S, Lange R, Schoenburg M, et al. Off-pump transapical implantation of artificial neo-chordae to correct mitral regurgitation: the TACT trial (transapical artificial chordae tendinae) proof of concept. J Am Coll Cardiol. 2014;63:914-9.

6. Caimmi PP, Sabbatini M, Fusaro L, Borrone A, Cannas M. A study of the mechanical properties of ePTFE suture used as artificial mitral chordae. J Card Surg. 2016;31:498-502.

7. Colli A, Manzan E, Aidietis A, Rucinskas K, Bizzotto E, Besola L, et al. An early European experience with transapical off-pump mitral valve repair with NeoChord implantation. Eur J Cardiothorac Surg. 2018 [In press].

8. Suri RM, Schaff HV, Dearani JA, Sundt TM III, Daly RC, Mullany CJ, et al. Survival advantage and improved durability of mitral repair for leaflet prolapse subsets in the current era. Ann Thorac Surg. 2006;82:819-26.

9. David TE, Ivanov J, Armstrong S, Christie D, Rakowski H. A comparison of outcomes of mitral valve repair for degenerative disease with posterior, anterior, and bileaflet prolapse. J Thorac Cardiovasc Surg. 2005;130:1242-9. 